\title{
Program Review Group
}

National Cancer Institute

\section{Source}

National Cancer Institute. Program Review Group. NCI Thesaurus. Code C19514.

The Program Review Groups function to examine the $\mathrm{NCl}$ extramural programs and their infrastructures to evaluate whether changes are necessary in order for the Institute to be in a position to effectively guide and administer the needs of the science in the foreseeable future. 